\title{
Cardiac Resynchronization Therapy in Patients with Mild Heart Failure: A Systematic Review and Meta-Analysis of Randomized Controlled Trials
}

\author{
Ronghui Tu • Guoqiang Zhong • Zhiyu Zeng • \\ Weifeng Wu • Hai Wu • Xiaoli Cao • \\ Lynn Htet Htet Aung \\ Published online: 13 July 2011 \\ (C) The Author(s) 2011. This article is published with open access at Springerlink.com
}

\begin{abstract}
Objective This review aims at updating the results of cardiac resynchronization therapy (CRT) in mild heart failure patients, and investigating whether CRT can prevent or reverse heart failure progression in an earlier stage. Methods Randomized controlled trials of CRT in patients with New York Heart Association (NYHA) Class I or II heart failure were identified. The effects of CRT on worsening heart failure hospitalization, all-cause mortality, and overall adverse events were meta-analyzed, and the effects of CRT on left ventricular (LV) were systematically reviewed and meta-analyzed.

Results Eight studies were identified with a total of 4,302 patients. CRT was associated with a substantial improvement in LVend-systolic volume (WMD -39, 95\% CI -41.56 to -36.45 ). CRT also had a marked effect in reducing new hospitalizations for worsening heart failure by $31 \%$ (RR 0.69 , $95 \%$ CI 0.60 to 0.79 ). In addition, CRT significantly decreased all-cause mortality by $21 \%$ (RR $0.79,95 \%$ CI 0.67 to 0.93 ). However, complications in patients with CRT increased by $74 \%$ (RR $1.74,95 \%$ CI 1.44 to 2.11 ).

Conclusions This meta-analysis suggests that CRT could improve the prognosis in patients with mild heart failure and ventricular dyssynchrony, but these improvements are accompanied by more adverse events. Since most patients in the included trials had received ICD therapy, our analysis suggests that CRT could offer an additional benefit.
\end{abstract}

Key words Heart failure · Cardiac resynchronization therapy· Meta-analysis

R. Tu $\cdot$ G. Zhong $(\bowtie) \cdot$ Z. Zeng $\cdot$ W. Wu $\cdot H$. Wu $\cdot$ X. Cao $\cdot$

L. H. H. Aung

Department of Geriatric Cardiology, First Afiliated Hospital, Guangxi Medical University,

22 Shuangyong Road,

530000, Nanning, Guangxi, People's Republic of China

e-mail: gq_zhong@yahoo.com

\section{Introduction}

Several large multi-center clinical trials have confirmed that CRT not only can improve heart function, exercise capacity and quality of life, but also reduce mortality and hospitalization, and it can even improve the prognosis in patients with moderate to severe heart failure (New York Heart Association [NYHA] class III/IV) [1-6]. These patients are characterized by severe heart failure symptoms, poor left ventricular (LV) systolic function (ejection fraction $[\mathrm{EF}] \leq 35 \%)$, and wide QRS $(\geq 120 \mathrm{~ms})$ on the surface ECG as a sign of ventricular dyssynchrony. However, for the advanced heart failure patients, especially those with NYHA IV, the duration of these beneficial effects afforded by CRT still remains unknown. It appears that slowing heart failure progression is the most important target. Subsequent trials, including the Multicenter Automatic Defibrillator Implantation Trial With Cardiac Resynchronization (MADITCRT) [7] and the extended follow-up of the Resynchronization Reverses Remodeling in Systolic Left Ventricular Dysfunction (REVERSE) substudy of the European patient cohort [8], were designed to test if CRT has clinical advantages in patients with milder heart failure and the results were encouraging. A meta-analysis of the MADITCRT and REVERSE trials in patients with CRT and implantable cardioverter-defibrillator (ICD) backup (CRT-D) reported a significant reduction in a composite outcome of heart failure events, but not mortality [9]. However, the recent results of Resynchronization/Defibrillation for Ambulatory Heart Failure Trial (RAFT) [10] showed the superiority of CRT in reducing mortality and the combined outcome of death from any cause or hospitalization related to heart failure among patients receiving optimal medical therapy and ICD.

The aim of this meta-analysis is to update the results of CRT in mild heart failure in terms of reverse LV 
remodeling, worsening heart failure hospitalization and all-cause mortality by collecting all available data, as well as the most recently published papers on CRT, and further explore whether CRT could prevent or reverse heart failure progression in patients with mild symptoms (NYHA Class I/II).

\section{Methods}

\section{Search strategy}

Electronic searches of MEDLINE, EMBASE, CENTREN and its affiliated clinical trial registration data center, US Food and Drug Administration reports, Chinese Biomedical Literature Database CD-ROM, VIP Chinese Science and Technology Periodical Database, and China National Knowledge Infrastructure databases from establishment to Dec 2010, using the search terms "CRT, heart failure", "biventricular pacer, heart failure", "biventricular pacing, heart failure", and "biventricular pacemaker, heart failure", were performed to identify randomized controlled trials (RCTs). Hand searches of bibliographies from published meta-analyses and review articles and proceedings booklets from conferences were also included to ensure inclusion of all pertinent studies for the preliminary review. In addition, we contacted authors of some studies and device manufacturers for additional citations and information. The searches were limited to studies published in the English and Chinese language but not to publication status.

\section{Eligibility criteria}

The types of participants considered were patients with NYHA Class I/II symptoms, low EF $(\leq 40 \%)$ and wide QRS ( $\geq 120 \mathrm{~ms}$ ). The NYHA Class was evaluated at baseline before randomization. The technology being evaluated is CRT, and the search strategy focused on RCTs in which an experimental group included CRT vs the control group. Studies were excluded if another report from the same trial with more updated data was available. RCTs with a less than 3 months follow-up or crossover trials with a less than 3 months follow-up during the first randomized crossover phase were also excluded. To avoid a carry-over effect, only the first randomized cross-over period was considered for analysis.

\section{Outcome assessment}

We assessed reverse LV remodeling, hospitalization for worsening heart failure, all-cause mortality, and overall adverse events.
Data extraction and quality assessment

Two investigators (Zhong G, Tu R) independently extracted data from each study. We used a standardized extraction form to evaluate the study quality, including the study design, length of follow-up and loss to follow-up, and blinding of patients and investigators. Disagreements were resolved by consensus with 5 other investigators (Zeng Z, Wu W, Wu H, Cao X, Aung LHH). The data we collected included clinical outcomes such as heart failure hospitalization, death from any cause, and adverse events associated with CRT, as well as basic data such as LV remodeling parameters, median QRS duration and EF for each study.

\section{Statistical analyses}

The statistical analyses were performed using the RevMan computer software (Cochrane Center: available at: http:// www.cochrane.org). Dichotomous outcomes were analyzed by calculating the relative risk (RR) and continuous outcomes were presented as a weighted mean difference (WMD). A fixed effects model was used to pool data from each trial. The $95 \%$ confidence intervals (CI) were used for safety analysis. Statistical heterogeneity was quantified using the chi-square test. When heterogeneity was present, a random effects model was calculated.

\section{Results}

Search results

A total of 1,391 relevant references from all databases were found (Fig. 1). Of these, full-text versions of 90 references were retrieved for detailed evaluation. Only eight trials fulfilled the inclusion criteria and were included in our meta-analysis. These were the Safety and Effectiveness of Cardiac Resynchronization Therapy With Defibrillation (CONTAK CD) [11], Multicenter InSync Implantable

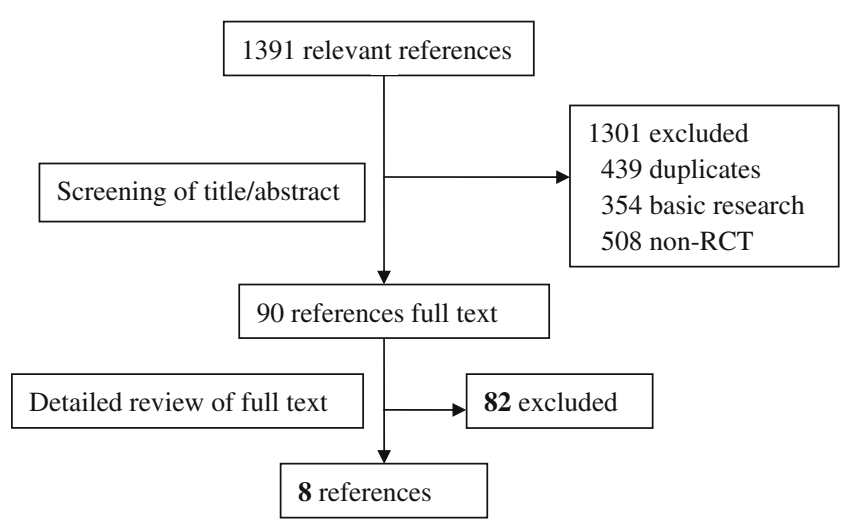

Fig. 1 Study flow 
Cardioversion Defibrillation Randomized Clinical Evaluation (MIRACLE ICD II) [12], the extension phase of Cardiac Resynchronization-Heart Failure (CARE-HF extension) [5, 13], MADIT-CRT [7], REVERSE Europe [8], RAFT [10], Evaluation of Resynchronization Therapy For Heart Failure In Patients With A QRS Duration Greater Than 120 ms (Greater EARTH) [14] and van Geldorp et al. [15] trials.

\section{Study and patient characteristics}

A total of 4,302 mild heart failure patients with median LVEF ranging from $21.5 \%$ to $28 \%$ and median QRS ranging from 155 to $195 \mathrm{~ms}$ were included. The baseline patient characteristics and design of the trials were described in Tables 1 and 2. 2 trials (298 patients) were restricted to patients with LVEF less than $40 \%$ [8, 15], 4 trials (972 patients) less than $35 \%[5,11,12,14]$, and 2 trials $(3,618$ patients) less than $30 \%$ [7, 10]. 3 trials $(2,268$ patients) enrolled patients with NYHA class I/II symptoms exclusively $[7,8,12]$, and in the other 5 trials, $21.5 \%-80 \%$ of patients had NYHA class I/II symptoms. The median age of the populations ranged between 61 and 66 years. The median follow-up ranged between 6 months and 40 months.

The majority of subjects in each trial were male and ischemic cardiomyopathy was the main etiology in five trials [7, 10-12, 14]. Most trials excluded patients with atrial fibrillation, and one trial evaluated the effects of CRT in this population [10]. 94\% of the control and $97.3 \%$ of the CRT patients in the trials received an ICD and the use of medical therapy like ACE inhibitors, angiotensin-receptor blockers, and diuretics was comparably high. In contrast, beta-blockers treatment ranged from $47 \%$ in CONTAK CD to $93.4 \%$ in REVERSE Europe. In five trials, all patients received CRT devices and were randomized in a parallel way $[8,11,12]$ or crossover design $[14,15]$ to CRT on or off. In the three largest trials $[5,7,10]$, patients were randomized with or without receiving a CRT device.

\section{Reverse left ventricular remodeling}

Five trials $[7,8,11,12,15]$ assessed the effect of CRT on LV remodeling by comparing baseline and endpoint echocardiographic parameters. CRT had been shown to improve LV remodeling parameters of heart failure in each study (Table 3). When limited to 6 months follow-up, CONTAK CD [11], MIRACLE ICD II [12] and van Geldorp et al. [15] showed a positive effect on LV structure and function with CRT in NYHA Class I/II patients. In the CONTAK CD [11], CRT demonstrated significant reductions in LV internal diameter in diastole and systole $(-2.4 \pm 0.8$ vs. $0.0 \pm 0.8 \mathrm{~mm}, P=0.024$ and $-3.2 \pm 0.8$ vs. $-0.5 \pm 0.8 \mathrm{~mm}, P=0.014$, respectively). In the MIRACLE ICD II [12], CRT patients showed a significant reduction in $\mathrm{LV}$ end-diastolic and end-systolic volumes $(-41 \pm 76$ vs. $-16 \pm 62 \mathrm{ml}, P=0.04$ and $-42 \pm 77$ vs. $-14 \pm$ $57 \mathrm{ml}, P=0.01$, respectively) and a significant increase in LVEF $(3.8 \pm 8.0 \%$ vs. $0.8 \pm 6.2 \%, P=0.02)$. A similar improvement in LVEF $(12 \pm 11 \%$ vs $.5 \pm 11 \%)$, in association with LV end-diastolic and end-systolic diameters $(-4 \pm 7$ vs. $-1 \pm 7 \mathrm{~mm}$ and $-5 \pm 8$ vs. $-2 \pm 8 \mathrm{~mm}$, respectively) and volumes $(-39 \pm 70$ vs. $-13 \pm 57 \mathrm{ml}$ and $-41 \pm 61$ vs. $-15 \pm$ $55 \mathrm{ml}$, respectively) was reported with CRT in van Geldorp et al. [15]. At 12 months of follow-up, MADIT-CRT [7] revealed a significant improvement in LV end-systolic volume index (LVESVi) $\left(-26.2 \pm 16.5\right.$ vs. $-7.4 \pm 7.2 \mathrm{~mL} / \mathrm{m}^{2}$, $P=0.0001)$ and $\mathrm{LV}$ end - diastolic volume index (LVEDVi) $\left(-28.7 \pm 15.5\right.$ vs. $\left.-9.1 \pm 8.2 \mathrm{~mL} / \mathrm{m}^{2}, P=0.0001\right)$ in association with LVEF $(11 \pm 5 \%$ vs. $3 \pm 3 \%, P=0.0001)$ with CRT. LV diameters, LV end-diastolic volume, LV end-systolic volume (LVESV), and left atrial volume were also significantly reduced to a greater extent in the CRT group in this trial. After 24 months follow-up, REVERSE Europe [8] demonstrated that LVESVi decreased by a mean of $27.5 \pm 31.8 \mathrm{~mL} / \mathrm{m}^{2}$ in the CRT-ON group compared with $2.7 \pm 25.8 \mathrm{~mL} / \mathrm{m}^{2}$ in the CRT-OFF group $(P<0.0001)$. LVEDVi and LVEF had similarly greater changes in the CRT ON than in the CRT OFF group.

As the most obvious parameter of reverse remodeling, LVESV was included in this meta-analysis to assess the effects of CRT on reverse left ventricular remodeling. Three trials [7, 12, 15] were included into a meta-analysis showing that CRT had a marked effect on improvement in LVESV (WMD $-39,95 \%$ CI -41.56 to -36.45 ; Fig. 2). No statistical heterogeneity was found among the trials $\left(\mathrm{I}^{2}=0 \%, P=0.51\right)$.

\section{Heart failure hospitalization}

Six trials $[7,8,10-12,14]$ provided data on patients experiencing heart failure related hospitalization. Four studies showed an absolute reduction in heart failure hospitalization in patients treated with CRT. When pooling the data together (4,039 patients), a significant relative reduction of $31 \%$ in this endpoint was observed among patients treated with CRT (RR $0.69,95 \%$ CI 0.60 to 0.79 , Fig. 3). No evidence of statistical heterogeneity was observed between trials regarding this effect $\left(\mathrm{I}^{2}=29 \%\right.$, $P=0.21$ ).

All-cause mortality

Data on the all-cause mortality was obtained for each trial. Only the RAFT trial [10] reported a statistically significant reduction in all-cause mortality in patients with CRT as 


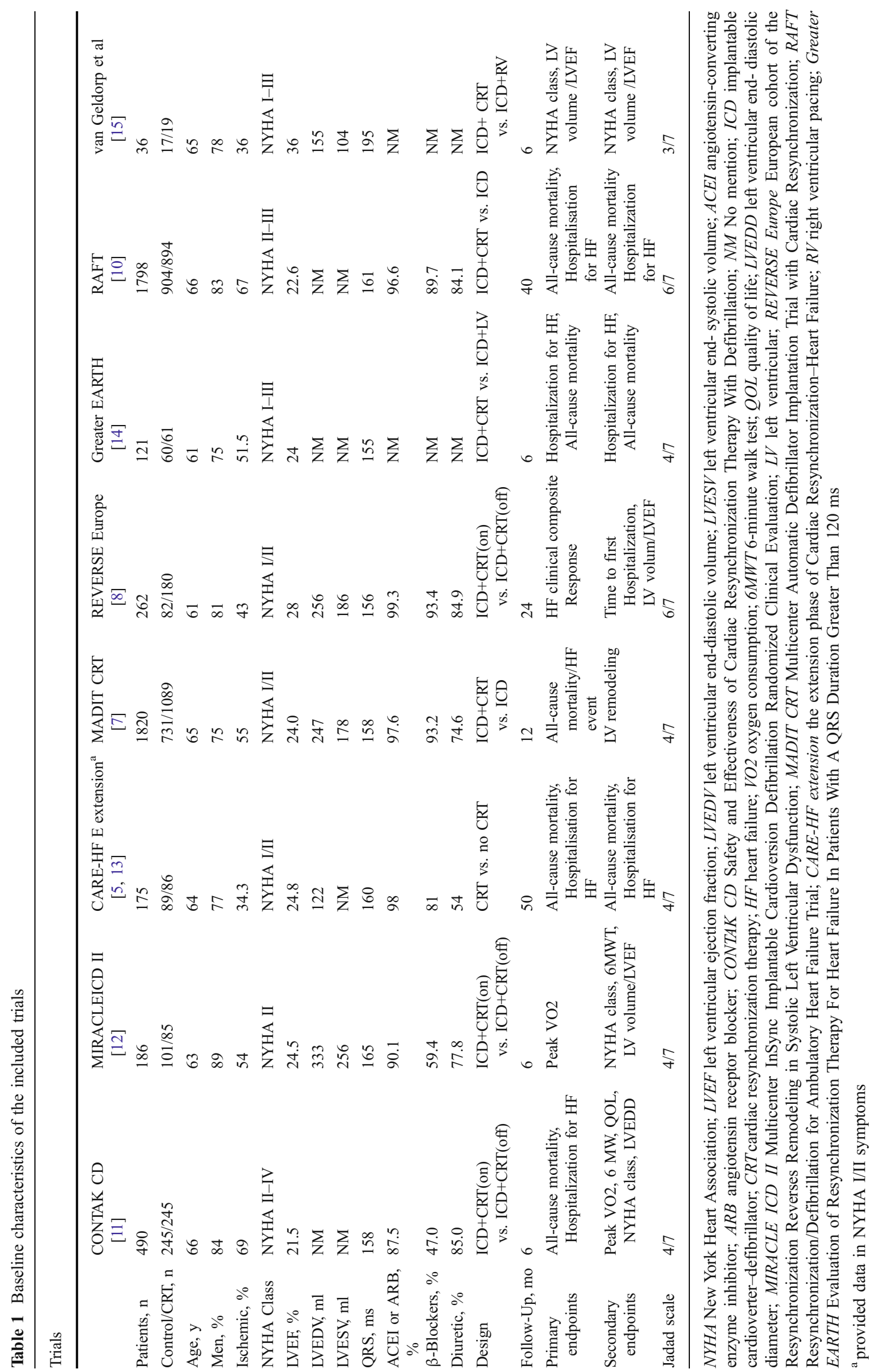


Table 2 Patient features between control arm and CRT arm

\begin{tabular}{lll}
\hline & Control & CRT \\
\hline Patients, n & 1937 & 2453 \\
Age, y & 64.4 & 63.7 \\
Men, \% & 79.2 & 79.0 \\
Ischaemic, \% & 55.3 & 54.5 \\
Atrial fibrillation or flutter,\% $\%$, $\%$ & 5.8 & 4.4 \\
LVEF, $\%$ QRS, ms & 23.9 & 24.3 \\
ACEI or ARB, \% & 182.8 & 166.8 \\
$\beta-b l o c k e r s, \%$ & 95.9 & 95.4 \\
Diuretic, \% & 79.3 & 81.0 \\
NYHA II, \% & 80.6 & 83.4 \\
ICD, \% & 74.6 & 74.3 \\
\hline
\end{tabular}

$L V E F$ left ventricular ejection fraction; $A C E I$ angiotensin-converting enzyme inhibitor; $A R B$ angiotensin receptor blocker; $N Y H A$ New York Heart Association; ICD implantable cardioverter-defibrillator; $C R T$ cardiac resynchronization therapy

compared to the control group (RR $0.74,95 \%$ CI 0.59 to 0.92 ). When pooling data from all studies together (4,302 patients), we found that CRT significantly reduced all-cause mortality by $21 \%$ (RR $0.79,95 \%$ CI 0.67 to 0.93 ) compared to the control group (Fig. 4). No heterogeneity was observed among RRs for all-cause mortality reported in the studies $\left(\mathrm{I}^{2}=0 \%, P=0.68\right)$.

\section{Complications}

Four trials [7, 8, 10, 12] mentioned complications or adverse events for device implantation. In two of these, both CRT groups [8, 12] reported the percentage of patients with complications, consisting mainly of lead dislodgements which occurred $8.5 \%$ during peri-implantation and 5.9\% after implantation. Only one trial [8] provided complications separately, and no significant difference was found between the two groups (RR $1.04,95 \% \mathrm{CI} 0.45$ to 2.43 ). The other two largest trials [7, 10] reported that adverse events within 30 days after device implantation was significantly higher among patients in the CRT-D group than among those in the ICD-only group (RR 1.79 , 95\%CI 1.47 to 2.18). In Fig. 5 the forest plot indicates that the complications in patients with CRT increased by 74\% compared with the control group (RR $1.74,95 \%$ CI 1.44 to 2.11 ) after pooling the data from three trials $[7,8,10]$. No evidence of statistical heterogeneity was reported $\left(\mathrm{I}^{2}=6 \%, P=0.35\right)$.

\section{Discussion}

Over 4,000 patients were evaluated in this meta-analysis on CRT in mild heart failure patients with left ventricular systolic dysfunction and broad QRS complex. The results showed that CRT improved LVESV $(P<0.00001)$, reduced new hospitalizations for worsening heart failure by $31 \%$ $(P<0.00001)$ and all-cause mortality by $21 \%(P=0.006)$. Compared with the published meta-analyses [16, 17], firstly, the present study included more trials, which demonstrates the convincing effect of CRT on mortality and morbidity in mild heart failure patients. Secondly, the result of our meta-analysis show that the complications in patients with CRT increased by $74 \%(P<0.00001)$. Given the fact that the follow-up period might be an important factor to detect an improvement in patients with mild heart failure, another noted difference is that we used the extended follow-up of the REVERSE trial [18]: 24-month clinical and left ventricular remodeling outcomes which were reported by the European cohort.

In the current study, we found that CRT could improve LVESV in patients with NYHA I/II symptoms, which is consistent with the other studies [19, 20]. These improvements were accompanied by a significant delay in time to first heart failure hospitalization or death, indicating that reverse remodeling by CRT was linked to reduced morbidity and mortality [7, 8, 21]. It is worth mentioning that MADITCRT [7] also showed a significant reduction in left atrial volume. Most likely, this reduction will lead to a lower incidence of new-onset atrial fibrillation. Reducing the occurrence of atrial fibrillation will further help prevent progression of heart failure [22]. Therefore, our analyses suggest that CRT was associated with a long-term beneficial effect on disease progression in mild heart failure patients.

An important finding in our analyses was the significant decrease in all-cause mortality seen after CRT. CRT has previously been demonstrated to reduce all-cause mortality in patients with NYHA class III and IV symptoms [4, 5]. Only recently the RAFT trial [10] demonstrated a significant reduction in overall mortality in NYHA class I/II patients with CRT. Prior to RAFT, CARE HF, in which 175 patients who reported themselves to be in NYHA class I/II, but were assessed as NYHA class III/IV, also benefitted from CRT with respect to the combined outcome of all-cause mortality or hospitalization for heart failure [13], and so did the Comparison of Medical therapy, Pacing and Defibrillation in Heart Failure study (COMPANION) [4].

Early studies such as CONTAK CD and MIRACLE ICD II also measured symptoms like NYHA class, which did not change significantly after 6 months of CRT compared with the control treatment. This was not unexpected, given the fact that patients with NYHA class I/II heart failure had a smaller symptom burden and the observation time for such improvements needs to be longer than 6 months. As objective assessments of circulatory capacity and respiratory response to exercise, peak oxygen consumption(peak $\mathrm{VO}_{2}$ ) and minute ventilation/minute carbon dioxide production 


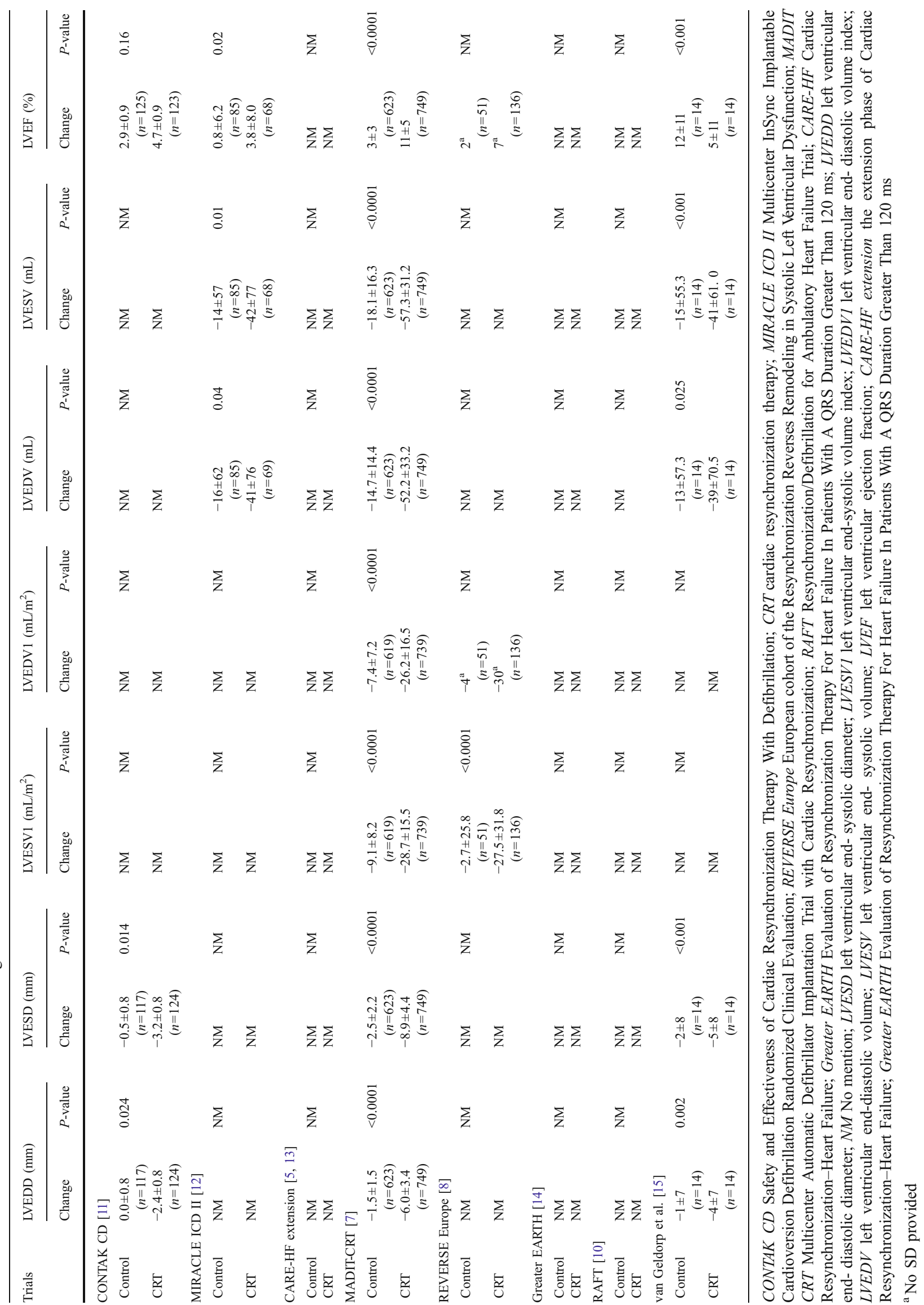




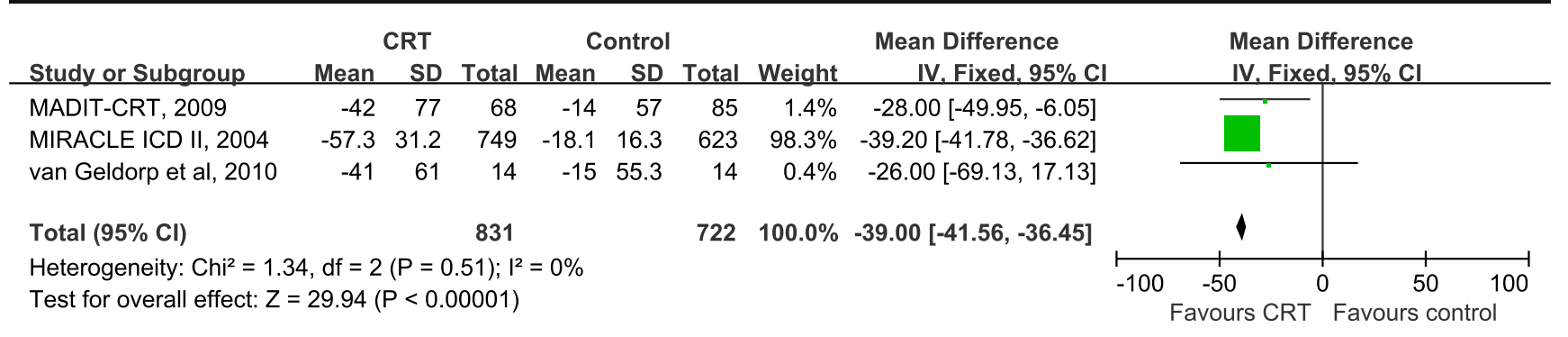

Fig. 2 Forest plot demonstrated the effects of CRT on LVESV, mean difference and 95\% confidence intervals. Outcomes were pooled using fixed-effects modeling

$\left(\mathrm{VE} / \mathrm{VCO}_{2}\right)$ are important cardiopulmonary exercise test parameters and known powerful predictor of prognosis [23, 24], these parameters have been used qualifying patients for implantation and evaluating the results of therapy in many studies with CRT [12, 25-27]. However, VE/VCO 2 , but not peak $\mathrm{VO}_{2}$ was improved by CRT in NYHA I/II heart failure patients $[11,12]$. It is difficult to explain this difference, as only one trial [12] measured both parameters in this population.

As $94 \%$ in the control and $97.3 \%$ in the CRT had an ICD in our meta-analyses, the benefits of CRT in our study represent additional benefits to those expected from the ICD alone. Further, there is some current evidence supporting the use of CRT-D in these populations. However, CRT-D seemed to be associated with a higher risk of devicerelated complications such as LV lead repositioning, infection incidences, pneumothorax, pocket hematomas requiring evacuation, and coronary venous dissection as compared with ICD [28-30]. Although many of these adverse events did not have substantial long-term consequences, they may have caused substantial morbidity and increased the overall cost to health care systems. Since the economic feasibility of CRT implantation in patients with mild heart failure remains uncertain [31], it is of utmost importance to assess how patients can maximally benefit from CRT. Nowadays, structured exercise training has been widely accepted in patients with CRT to further improve the functional status, and to ensure the best possible outcome from CRT [32].

It is noteworthy that patients with less severe LV dysfunction (LVEF $>35 \%$ or more) appear to acquire significant clinical and structural benefit from CRT [14, 33]. Currently, up to $22 \%$ of patients receiving CRT have NYHA Class I or II symptoms and up to $17 \%$ have a LVEF above 35\% [34]. The European Society of Cardiology has extended its recommendation for CRT to patients with NYHA class II symptoms, LVEF of $35 \%$ or less, wide QRS duration of $150 \mathrm{~ms}$ or more, and sinus rhythm [35]. Moreover, it is expected that it might even be extended to diastolic heart failure with a preserved $\mathrm{EF}$ in future studies [36].

\section{Limitations of the study}

A number of limitations of the present analysis should be noted. Firstly, though the specific cause of death was reported in two studies [8, 10], only one of them[10] reported this separately, so we can only access all-cause mortality. Secondly, the data of echocardiographic parameters were partially reported in most trials and were not consistently

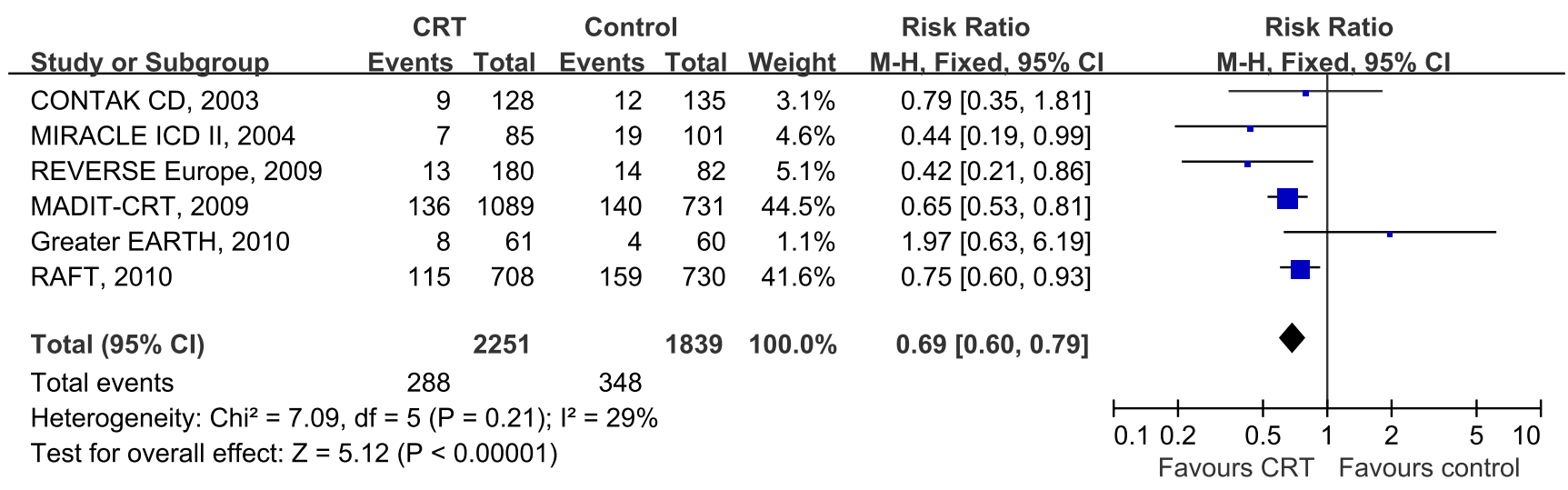

Fig. 3 Forest plot demonstrated the effects of CRT on heart failure hospitalization, risk ratio and $95 \%$ confidence intervals. Outcomes were pooled using fixed-effects modeling 


\begin{tabular}{|c|c|c|c|c|c|c|c|c|c|}
\hline Study or Subgroup & $\begin{array}{l}\text { CRT } \\
\text { Events }\end{array}$ & Total & $\begin{array}{l}\text { Contr } \\
\text { Events }\end{array}$ & $\begin{array}{l}\text { ol } \\
\text { Total }\end{array}$ & Weight & $\begin{array}{c}\text { Risk Ratio } \\
\text { M-H, Fixed, 95\% Cl }\end{array}$ & & $\begin{array}{c}\text { Risk Ratio } \\
\text { M-H, Fixed, 95\% Cl }\end{array}$ & \\
\hline CONTAK CD, 2003 & 0 & 128 & 5 & 135 & $2.1 \%$ & $0.10[0.01,1.72]$ & & & \\
\hline MIRACLE ICD II, 2004 & 2 & 85 & 2 & 101 & $0.7 \%$ & $1.19[0.17,8.26]$ & & & \\
\hline CARE-HF extension, 2006 & 23 & 86 & 27 & 89 & $10.2 \%$ & $0.88[0.55,1.41]$ & & & \\
\hline REVERSE Europe, 2009 & 10 & 180 & 7 & 82 & $3.7 \%$ & $0.65[0.26,1.65]$ & & & \\
\hline MADIT-CRT, 2009 & 74 & 1089 & 53 & 731 & $24.4 \%$ & $0.94[0.67,1.32]$ & & & \\
\hline Greater EARTH, 2010 & 2 & 61 & 2 & 60 & $0.8 \%$ & $0.98[0.14,6.76]$ & & & \\
\hline RAFT, 2010 & 110 & 708 & 154 & 730 & $58.2 \%$ & $0.74[0.59,0.92]$ & & & \\
\hline van Geldorp et al, 2010 & 0 & 19 & 0 & 18 & & Not estimable & & & \\
\hline Total $(95 \% \mathrm{Cl})$ & & 2356 & & 1946 & $100.0 \%$ & $0.79[0.67,0.93]$ & & & \\
\hline Total events & 221 & & 250 & & & & & & \\
\hline $\begin{array}{l}\text { Heterogeneity: } \mathrm{Chi}^{2}=4.01 \text {, } \\
\text { Test for overall effect: } Z=2\end{array}$ & $\begin{array}{l}=6(P= \\
7(P=0 . C\end{array}$ & $\begin{array}{l}0.68) ; ~ I \\
06)\end{array}$ & $2=0 \%$ & & & & $\begin{array}{l}0.10 .2 \\
\text { Favc }\end{array}$ & $\begin{array}{ccc}0.5 & 1 & 2 \\
\text { urs } \mathrm{CRT} & \text { Favours co }\end{array}$ & $\begin{array}{ll}510 \\
510 \\
\text { ontrol }\end{array}$ \\
\hline
\end{tabular}

Fig. 4 Forest plot demonstrated the effects of CRT on all-cause mortality, risk ratio and $95 \%$ confidence intervals. Outcomes were pooled using fixed-effects modeling

provided in a poolable format (Table 3 ). As a result, we evaluated the effects of CRT on left ventricular remodeling by systematical review and meta-analysis of LVESV. Thirdly, NYHA class is in fact not a fixed or highly reproducible measurement, which will fluctuate over time in response to changes in organ function, mood, expectations, and exercise training [32] in individual patients. To some extent, it may not be appropriate to select patients for CRT on the basis of severity of their symptoms in the presence of LV dysfunction and markers of dyssynchrony [13]. After all, the objective of treatment is to improve long-term prognosis. Finally, this meta-analysis included only 8 RCTs and one of them was a retrospectively defined analysis [13]. More randomized trials with a longer follow-up are needed to better evaluate the effect of CRT in mild heart failure patients.

\section{Conclusion}

In summary, our analysis shows that standard pharmacologically managed mild heart failure patients with ventricular dyssynchrony substantially benefit from CRT in terms of reverse LV remodeling and reducing heart failure hospitaliza-

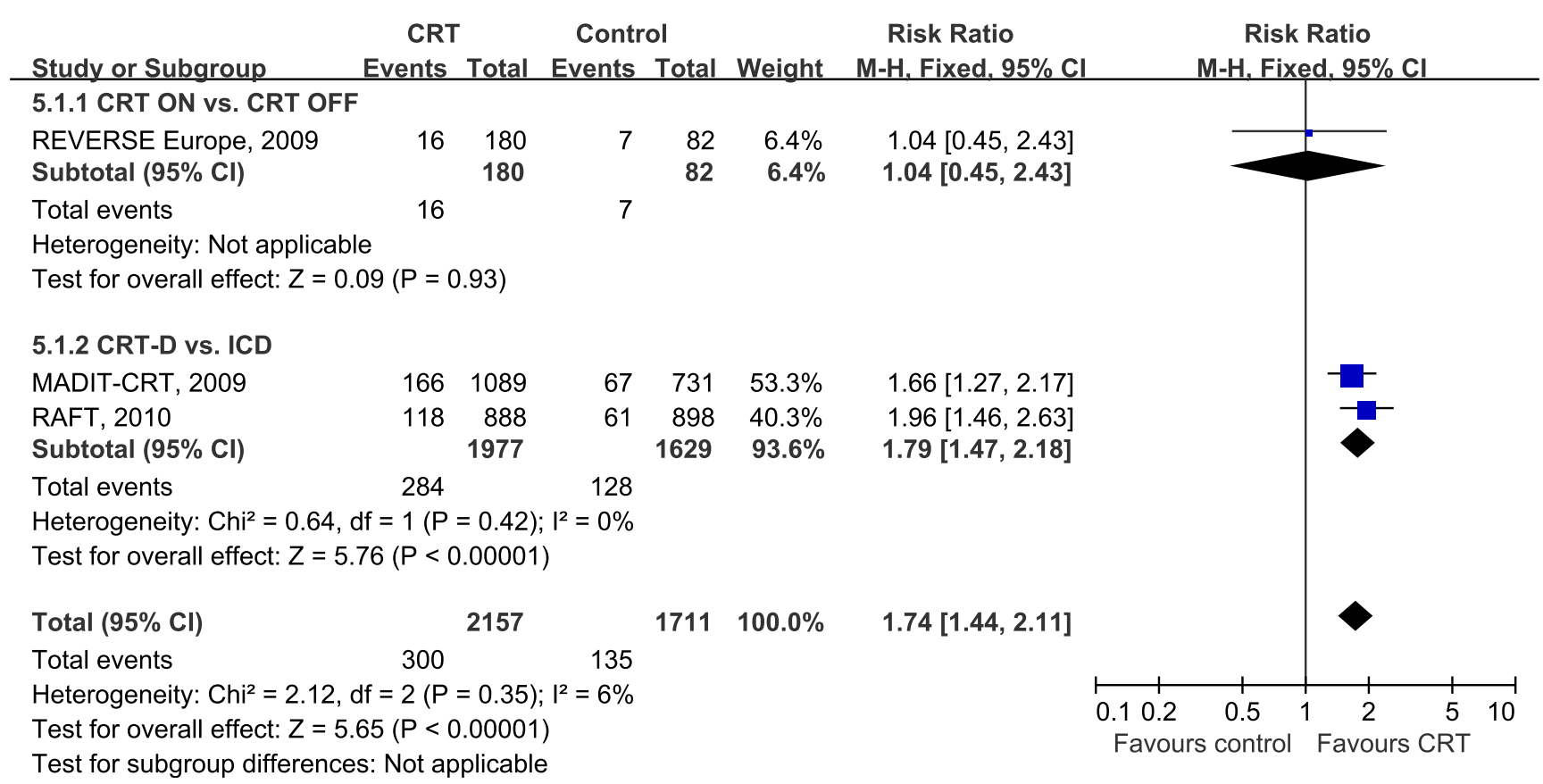

Fig. 5 Forest plot demonstrated the complications with CRT, risk ratio and 95\% confidence intervals. Outcomes were pooled using fixed-effects modeling 
tion and all-cause mortality. Since most patients in the included trials received ICD therapy, our analysis suggests that CRT may offer a benefit additional to that of ICD. This meta-analysis also indicates that prevention of disease progression could be well accomplished by CRT in mild heart failure patients. However, these benefits were accompanied by more adverse events.

Acknowledgments We thank Dr. William T. Abraham, Division of Cardiovascular Medicine, The Ohio State University, Columbus, and Dr. Brett J. Peterson, Medtronic Inc, Minneapolis, Minn, for providing additional data. We also thank Dr. Ningqin Qi, Dr. Xianyan Tang and Dr. Xiaobo Yang, Department of Epidemiology \& Health Statistics, Guangxi Medical University, Shuangyong Road, Nanning, for their technical assistance.

Open Access This article is distributed under the terms of the Creative Commons Attribution Noncommercial License which permits any noncommercial use, distribution, and reproduction in any medium, provided the original author(s) and source are credited.

\section{References}

1. Cazeau S, Leclercq C, Lavergne T, Walker S, Varma C, Linde C, et al. Effects of multisite biventricular pacing in patients with heart failure and intraventricular conduction delay. $\mathrm{N}$ Engl $\mathrm{J}$ Med. 2001;344:873-80.

2. Abraham WT, Fisher WG, Smith AL, Delurgio DB, Leon AR, Loh E, et al. Cardiac resynchronization in chronic heart failure. $\mathrm{N}$ Engl J Med. 2002;346:1845-53.

3. Young JB, Abraham WT, Smith AL, Leon AR, Lieberman R, Wilkoff $\mathrm{B}$, et al. Combined cardiac resynchronisation and implantable cardioversion defibrillation in advanced chronic heart failure: the MIRACLE ICD trial. JAMA. 2003;289:2685-94.

4. Bristow MR, Saxon LA, Boehmer J, Krueger S, Kass DA, De Marco T, et al. Cardiac resynchronization therapy with or without an implantable defibrillator in advanced chronic heart failure. $\mathrm{N}$ Engl J Med. 2004;350:2140-50.

5. Cleland JGF, Daubert JC, Tavazzi L, Erdmann E, Freemantle N, Gras D, et al. Longer-term effects of cardiac resynchronization therapy on mortality in heart failure [the Cardiac REsynchronization-Heart Failure (CARE-HF) trial extension phase]cardiac resynchronization on mortality in the CARE-HF extension study. Eur Heart J. 2006;27:1928-32.

6. Auricchio A, Stellbrink C, Sack S, Block M, Vogt J, Bakker P, et al. Long term effect of hemodynamically optimized cardiac resynchronization therapy in patients with heart failure and ventricular conduction delay. J Am Coll Cardiol. 2002;39:2026-33.

7. Moss AJ, Hall WJ, Cannom DS, Klein H, Brown MW, Daubert JP, et al. Cardiac resynchronization therapy for the prevention of heart-failure events. N Engl J Med. 2009;361:1329-38.

8. Daubert C, Gold MR, Abraham WT, Ghio S, Hassager C, Goode $\mathrm{G}$, et al. Prevention of disease progression by cardiac resynchronization therapy in patients with asymptomatic or mildly symptomatic left ventricular dysfunction: insights from the European cohort of the REVERSE (Resynchronization Reverses Remodeling in Systolic Left Ventricular Dysfunction) trial. J Am Coll Cardiol. 2009;54:1837-46.

9. Lubitz SA, Leong-Sit P, Fine N, Kramer DB, Singh J, Ellinor PT. Effectiveness of cardiac resynchronization therapy in mild congestive heart failure: systematic review and meta-analysis of randomized trials. Eur J Heart Fail. 2010;12:360-6.
10. Tang AS, Wells GA, Talajic M, Arnold MO, Sheldon R, Connolly $\mathrm{S}$, et al. Cardiac-Resynchronization therapy for Mild-to-Moderate heart failure. N Engl J Med. 2010;363:2385-95.

11. Higgins SL, Hummel JD, Niazi IK, Giudici MC, Worley SJ, Saxon LA, et al. Cardiac resynchronization therapy for the treatment of heart failure in patients with intraventricular conduction delay and malignant ventricular tachyarrythmias. J Am Coll Cardiol. 2003;42:1454-59.

12. Abraham WT, Young JB, León AR, Adler S, Bank AJ, Hall SA, et al. Effects of cardiac resynchronization on disease progression in patients with left ventricular systolic dysfunction, an indication for an implantable cardioverter-defibrillator, and mildly symptomatic chronic heart failure. Circulation. 2004;110:2864-68.

13. Cleland JGF, Freemantle N, Daubert JC, Toff WD, Leisch F, Tavazzi L. Long-term effect of cardiac resynchronisation in patients reporting mild symptoms of heart failure: a report from the CARE-HF study. Heart. 2008;94:278-83.

14. Thibault B, Ducharme A, Harel F, White M, O'Meara E, Roy D, et al. Evaluation of resynchronization therapy for heart failure in patients with a QRS duration greater than $120 \mathrm{~ms}$ : The GreaterEARTH Trial. Presented at Heart Rhythm Society 31st Annual Scientific Sessions, Denver, Colorado, 13 May 2010.

15. van Geldorp IE, Vernooy K, Delhaas T, Prins MH, Crijns HJ, Prinzen FW, et al. Beneficial effects of biventricular pacing in chronically right ventricular paced patients with mild cardiomyopathy. Europace. 2010;12:223-9.

16. Al-Majed NS, McAlister FA, Bakal JA, Ezekowitz JA. Meta-analysis: cardiac resynchronization therapy for patients with less symptomatic heart failure. Ann Intern Med. 2011;154:401-12.

17. Wells G, Parkash R, Healey JS, Talajic M, Arnold JM, Sullivan S, et al. Cardiac resynchronization therapy: a meta-analysis of randomized controlled trials. CMAJ. 2011;183:421-9.

18. Linde C, Abraham WT, Gold MR, St John Sutton M, Ghio S, Daubert $\mathrm{C}$, et al. Randomized trial of cardiac resynchronization in mildly symptomatic heart failure patients and in asymptomatic patients with left ventricular dysfunction and previous heart failure symptoms. J Am Coll Cardiol. 2008;52:1834-43.

19. Bleeker GB, Schalij MJ, Holman ER, Steendijk P, van der Wall EE, Bax JJ. Cardiac resynchronization therapy in patients with systolic left ventricular dysfunction and symptoms of mild heart failure secondary to ischemic or nonischemic cardiomyopathy. Am J Cardiol. 2006;98:230-5.

20. Landolina M, Lunati M, Gasparini M, Santini M, Padeletti L, Achilli A, et al. Comparison of the effects of cardiac resynchronization therapy in patients with class II versus class III and IV heart failure (from the InSync/InSync ICD Italian Registry). Am J Cardiol. 2007;100:1007-12.

21. St John Sutton MG, Plappert T, Abraham WT, Smith AL, DeLurgio DB, Leon R, et al. Effect of cardiac resynchronization therapy on left ventricular size and function in chronic heart failure. Circulation. 2003;107:1985-90.

22. Borleffs CJ, Ypenburg C, van Bommel RJ, Delgado V, van Erven L, Schalij MJ, et al. Clinical importance of new-onset atrial fibrillation after cardiac resynchronization therapy. Heart Rhythm. 2009;6:305-10.

23. Mancini DM, Eisen H, Kussmaul W, Mull R, Edmunds Jr LH, Wilson JR. Value of peak exercise oxygen consumption for optimal timing of cardiac transplantation in ambulatory patients with heart failure. Circulation. 1991;83:778-86.

24. Ponikowski P, Francis DP, Piepoli MF, Davieset LC, Chua TP, Davos $\mathrm{CH}$, et al. Enhanced ventilatory response to exercise in patients with chronic heart failure and preserved exercise tolerance: marker of abnormal cardiorespiratory reflex control and predictor of poor prognosis. Circulation. 2001;103:967-72.

25. Auricchio A, Stellbrink C, Butter C, Sack S, Vogt J, Misier AR, et al. Clinical efficacy of cardiac resynchronization therapy using left 
ventricular pacing in heart failure patients stratified by severity of ventricular conduction delay. J Am Coll Cardiol. 2003;42:2109-16.

26. Chwyczko T, Sterliński M, Maciagg A, Firek B, Łabęcka A, Jankowska A, et al. Impact of cardiac resynchronisation therapy on adaptation of circulatory and respiratory systems to exercise assessed by cardiopulmonary exercise test in patients with chronic heart failure. Kardiol Pol. 2008;66:406-12.

27. Tse HF, Siu CW, Lee KL, Fan K, Chan HW, Tang MO, et al. The incremental benefit of rate-adaptive pacing on exercise performance during cardiac resynchronization therapy. J Am Coll Cardiol. 2005;46:2292-7.

28. Romeyer-Bouchard C, Da Costa A, Dauphinot V, Messier M, Bisch L, Samuel B, et al. Prevalence and risk factors related to infections of cardiac resynchronization therapy devices. Eur Heart J. 2010;31:203-10.

29. León AR, Abraham WT, Curtis AB, Daubert JP, Fisher WG, Gurley J, et al. Safety of transvenous cardiac resynchronization system implantation in patients with chronic heart failure: combined results of over 2,000 patients from a multicenter study program. J Am Coll Cardiol. 2005;46:2348-56.

30. Duray GZ, Schmitt J, Cicek-Hartvig S, Hohnloser SH, Israel CW. Complications leading to surgical revision in implantable cardioverter defibrillator patients: comparison of patients with singlechamber, dualchamber, and biventricular devices. Europace. 2009;11:297-302.
31. Rickard J, Wilkoff BL. Pivotal trials of cardiac resynchronization therapy: evolution to therapy in mild heart failure. J Interv Card Electrophysiol. 2011. [Epub ahead of print].

32. Patwala AY, Woods PR, Sharp L, Goldspink DF, Tan LB, Wright DJ. Maximizing patient benefit from cardiac resynchronization therapy with the addition of structured exercise training: a randomized controlled study. J Am Coll Cardiol. 2009;53:2332-9.

33. Chung ES, Katra RP, Ghio S, Bax J, Gerritse B, Hilpisch K, et al. Cardiac resynchronization therapy may benefit patients with left ventricular ejection fraction $>35 \%$ : a PROSPECT trial substudy. Eur J Heart Fail. 2010;12:581-7.

34. Dickstein K, Bogale N, Priori S, Auricchio A, Cleland JG, Gitt A, et al. The European cardiac resynchronization therapy survey. Eur Heart J. 2009;30:2450-60.

35. Dickstein K, Vardas PE, Auricchio A, Daubert JC, Linde C, McMurray J, et al. 2010 focused update of ESC Guidelines on device therapy in heart failure: an update of the 2008 ESC Guidelines for the diagnosis and treatment of acute and chronic heart failure and the 2007 ESC Guidelines for cardiac and resynchronization therapy. Developed with the special contribution of the Heart Failure Association and the European Heart Rhythm Association. Eur J Heart Fail. 2010;12:1143-53.

36. Maass AH, van Veldhuisen DJ. Device therapy in patients with heart failure and preserved ejection fraction (HFPEF): a new frontier? Eur J Heart Fail. 2010;12:527-9. 